Dangers to gear become more efficiently avoided. Inventors constantly try to make the gear more deadly. So the stock is driven down the $S$-shaped curve, until the ratio of effort to yield becomes so great as to be unprofitable. Here a sad equilibrium is established, with the fortunate few making a profit, most fishermen just covering expenses, but persisting in the hope of a favourable fluctuation, some making losses. So long as the rate of fishing is not deliberately held at a fixed level, this quagmire effectively holds the industry. If anything, such as mesh regulations, marketing schemes or cheaper fuel, promises more profit, there is a tendency for the rate of fishing to rise. Banks are more willing to lend money, owners more willing to replace ships and gear, better men are more willing to become fishermen. But if the rate of fishing rises, the stock goes further down the $S$-shaped curve, to a less profitable level. So the profit in a highly developed fishery is remarkably like the crock of gold at the foot of the rainbow.

If, however, the rate of fishing could be held at a fixed level, including fishing of all nations on a given stock, there is no reason why such measures should not be profitable.

There seems, however, to be a more fruitful source of profit in a definite reduction of the rate of fishing, for this, properly arranged, means reduction of the running expenses of fishing. It is on this, the expenses side of the balance sheet, that the modern statement expects the main profit. For example, the first approximation estimates the maximum yield of demersal fish in the North Sea at fifteen per cent greater than the yield of recent years. But the rate of fishing to give this yield is estimated as to be reduced by twenty-five per cent, which is a greater figure.
An important technical difficulty is how the rate of fishing could be controlled, because size, speed, age and seaworthiness of vessels all affect the rate of fishing, as well as skill and zeal of the crew. Nevertheless, some sufficiently good limitation of the sum total of fishing power of all vessels together expended per annum, might be devised. The difficulty might, in theory at any rate, be tackled by a different approach, namely by fixing quotas of each species for each area. Apart from these important details, the choice is theoretically open as to whether reduction is in number of men and ships working, or time per annum during which they work.

At the present time, the future course of the industry is uncertain and the decline in number of fishermen makes the problem one of concern outside the section of the population that is financially interested. Under a recent voluntary scheme, some of the trawlers are laid up and others are operating under restriction, for the sake of regulating their markets. This is 'rationalization' as ordinarily understood. But the case, as outlined in this article, is something quite different -in fact unique-for rationalization in this case should mean a particular double process, namely, saving expense and giving the fish time to reach an age where the total nett growth of the stock is greater.

\section{BIBLIOGRAPHY}

Baranov, "On the Biological Basis of Fisheries" (Moscow, 1916). Reed and Pearl, J. Roy. Stat. Soc., 90 (1927).

Meek, "The Progress of Life" (London, 1930), p. 144.

Russell, J. Cons. Int. Expl. de la Mer, 6 (1931).

Hjort, Jahn and Ottestad, Hvalradets Skrifter, 7 (1933).

Thompson and Bell, Rep. Int. Fish. Comm., 8 (1934).

Graham, J. Cons. Int. Expl. de la Mer, 10 (1935); 12 (1938).

Kemp, Rep. Brit. Assoc., 85 (1938).

\title{
Chemical Research and Industry
}

$\mathrm{D}^{\mathrm{E}}$ EPENDING upon the mood or the point of view, it is equally easy to be surprised at the large, or concerned at the small, impression which a single laboratory can make on the pile of industrial--even national-chemical problems awaiting solution. To read the report of the Chemistry Research Board and the report of the Director of Chemical Research for the triennial period 1935-1938* is to learn with what vigour and success the study of a great variety of these problems is being undertaken in the Chemical Research Laboratory at Teddington. At the same

* Report of the Chemistry Research Board for the Triennial Period ended 31st December 1937; with Report of the Director of Chemical Research. Pp. vii $+146+7$ plates. (Department of Scientiflc and Industrial Research.) (London: H.M. Stationery Office, 1938.) 3s. net. time, one is tempted to wonder whether in these progressive, competitive, and anxious days a team of a dozen such laboratories, all concerned with fundamentals, taking the long view, undisturbed by the absence of immediate profit, yet at all points initiating, supporting, and supplementing the activities of private industrial research organizations, would prove supernumerary to the desirable national establishment. To wonder anything of the kind is perhaps itself a tribute to the significance of the Teddington laboratory and an appreciation of its work.

For greater convenience in administration, the work of the laboratory is divided into ten sections. Study of the corrosion of metals involves 
considerations ranging from the composition of rust and the velocity and mechanism of its formation, to the conditions under which metals are attacked in stagnant or moving salt solutions and to the corrosion of locomotive boiler tubes, water supply systems, and fire extinguishers. The use of magnesium-rich alloys of the electron type in the manufacture of fuel tanks has hitherto been handicapped by the corrosive action of 'leaded' fuels in the presence of water. The separate main constituents of the anti-knock mixture, when mixed singly with petrol and water, have little effect, but together they may give much trouble. It has been discovered that this severe corrosion can be entirely suppressed by the addition of 1 per cent of quinoline, which does not affect the antiknock properties of the fuel.

High-pressure research has included the synthesis of acetic acid from methyl alcohol and carbon monoxide and an extension to higher aliphatic acids, the manufacture of higher alcohols, and the production of acids from ketones and carbon monoxide. Thus acetone and carbon monoxide under pressure in presence of phosphoric acid afford acetic and trimethylacetic acids, apparently by condensation to mesityl oxide followed by hydrolytic fission to isobutylene and acetic acid, the former then affording trimethylacetic acid and hydrocarbons. Experiments on the catalytic production of higher from lower alcohols have led to the determination of optimum conditions, and to the observation that the carbon monoxide employed is not an indifferent gas, but plays some part in bringing about the reactions concerned. Incidentally, it has been found that, owing to the risk of explosions, great caution is needed in the use of di-isopropyl ether.

The researches on coal, tar, and rubber comprise, as would be expected, a great deal of work on hydrogenation. Coal, in the form of a colloidal suspension in a suitable oil, can be hydrogenated in a pipe system with 85 per cent conversion to oil. Experiments on the hydrogenation of naphthalene derivatives and of pyrene are also described. One interesting research was concerned with the composition of wood smoke as used in the curing of fish ; another had as its object the development of new uses for chlorinated rubber.

Chemotherapy is represented by important work on pyridines, cyclic diazalines, and arsenicals, one of which, 'neocryl', is being subjected to extensive clinical tests.

The synthetic resins studied were obtained from phenolic or ketonic sources; both X-ray and electrical methods have been used. It is concluded that phenolic resin films can best be regarded as composed of irregularly shaped aggregates which are in contact at some, but not all, of the chemically active points. Catechin and gambier can now be used in the manufacture of laminated and moulded products. It is remarked that the present industrial development of colourless resins lends interest to attempts to produce transparent, glass-like ketonic resins, the preparation of which promises to be a comparatively cheap process.

Of particular interest in connexion with water pollution is the observation that many resins from polyphenolic substances possess good baseexchange properties. Acid-exchange resins can also be prepared, so that it is possible to use these two types of resin successively to remove dissolved solids from tap water. In the example given, the reduction was from 36 parts to 1 part per 100,000 . An investigation has been made into the possibility of contamination of drinking water by lead arising from the use of water mains for earthing electrical apparatus. Although the necessary current would not be carried by house fuses, damage may occur to the outside of the pipes by this means. A method of sampling, whereby the actual amount of lead present in water used for drinking and cooking purposes can be ascertained, is of value in assessing the suitability of domestic water supplies from this point of view.

The report on microbiology refers to the bactericidal action of oxygen under pressure at temperatures little above the optimum growth temperature. The Rideal-Walker test for disinfectants has been examined, and it is found that constancy of results is very difficult to secure. In connexion with the differentiation of strains of micro-organisms, it has been shown that acclimatization to growth at temperatures higher than the general optimum varies with the strain, and that in some cases the outstanding difference is in the sodium chloride requirement. Thus, for each strain of $V$. aestuarii the salt concentration tolerated reflects its origin, whether from sea water, estuarial water, fresh water, or soil, in spite of prolonged sub-culturing on media free from sodium chloride.

Studies on road tar were concerned not only with composition but also with behaviour in the open air. The surface skin formed by the combined action of evaporation, oxygen, and light is more impervious than that produced by evaporation only.

General research includes work on compounds of rhenium, ruthenium, osmium, and iridium, on the occurrence of germanium and gallium in coal, on polypyridyls and phenanthridine derivatives, and on the production of carbazole from $o$-xenylamine.

The report on chemical engineering refers to the erection of a turbulent flow high-pressure plant, to a high-pressure flow meter, and to a study of the action of hydrogen on steels at high temperatures and pressures. 